\title{
Phenotypic Manifestation and Pericentric Inversion 6
}

We have observed a de novo pericentric inversion $6[\operatorname{inv}(6)(\mathrm{pter} \rightarrow$ p12::q15 $\rightarrow$ p12::q15 $\rightarrow$ qter)] in lymphocyte and fibroblasts cultures of a 15-month-old girl with multiple dysmorphic features, such as low birth weight, short stature, decreased bone age, mental retardation, delayed motor and speech development, macrocephaly, hypertelorism, broad and impressed nasal bridge, and seizures. There seemed to be no chromosomal imbalance and we wonder whether the clinical findings are coincidental or not. We would like to compare data on similar observations.

Angela Schmidt, Institut für Humangenetik, Universitätsklinikum, Hufelandstrasse 55, D-4300 Essen 1, Bundesrepublik Deutschland

\section{Multiple Y-Chromosomal Aberrations in a Patient with Mixed Gonadal Dysgenesis of XO/XY Type}

Lymphocyte cultures of a 12-year-old Greek individual with ambiguous genitalia raised as female revealed mixoploidy of four different cell types: (1) 75\% XO, (2) 21\% 46,X,dic(Yq), (3) $2 \% 47, X Y Y$, and (4) $2 \% 47, X, \operatorname{dic}(Y q), \operatorname{dic}(Y q)$.

Although the patient is not available for further studies, we would like to learn whether others have observed similar mixoploidies that must have arisen by both non-disjunction and breakage events.

Angela Schmidt, E. Passarge, Institut für Humangenetik, Universitätsklinikum, Hufelandstrasse 55, D-4300 Essen 1, Bundesrepublik Deutschland

\section{Sporadic Translocation, Inversion, and Marker Chromosome in Prenatal Diagnosis}

We observed two balanced de novo structural rearrangements [t(1;2)], [inv(3)], and a sporadic small extra chromosome in $50 \%$ of cells, in amniotic fluid cell cultures from 1400 patients. All three pregnancies resulted in phenotypically normal children and the prenatal cytogenetic findings were confirmed after birth.

We would like to exchange data on similar experiences in other laboratories.
Angela Schmidt, E. Passarge, Institut für Humangenetik, Universitätsklinikum, Hufelandstrasse 55, D-4300 Essen 1, Bundesrepublik Deutschland 